\title{
Categorising the Behavioural Toxicities of Antidepressants Proposals and Requirements
}

\author{
JAMES F. O'HANLON and HUGH FREEMAN
}

Proposals for categorising antidepressant drugs with respect to their potentials for causing 'behavioural toxicity' have recently been published (e.g. Kerr et al, 1991; Hindmarch \& Kerr, 1992; Sherwood \& Hindmarch, 1994). Without wishing to discredit the concept and fully appreciating its heuristic value, we believe that the particular system offered for making this categorisation needs reconsideration.

The system has been constructed with data drawn from one group's studies on healthy volunteer subjects, treated with single doses and tested with a set of three psychomotor tasks: critical flicker/ fusion frequency, choice reaction time, and, sometimes, tracking. The data for each parameter were combined across studies by 'meta analysis'. Although the statistical procedure was not described, it supposedly left the mean drug-placebo differences intact while reducing the error variance, thereby enabling the investigators to detect some significant drug effects that were not apparent in analyses confined to data from separate studies (e.g. compare Alford \& Hindmarch, 1990, to the above). A rank order was then constructed for discriminating between drugs which significantly impaired or improved subjects' performance relative to placebo.

However, no operational definition of behavioural toxicity has been offered in the relevant publications, so the criterion variable for validating performance in these particular tests appears to be lacking. If test performance impairment is to be used as a surrogate for degrees of a drug's behavioural toxicity in real life, it needs to be shown that one is equivalent to the other. So far as we know, in none of the aforementioned tests has performance ever been shown to correlate strongly with anything that could be scaled as a behaviourally toxic reaction. Doubtless all are quite sensitive to drug activity that is commonly described as sedating, just as they are to a host of both stable and transient physiological factors that may or may not reduce safety in activities like driving. But sedation, particularly to a mild degree, is not necessarily behaviourally toxic, nor is it the only drug effect that could be so conceived. Non-sedating selective serotonin re-uptake inhibitors (SSRIs) produce nausea and insomnia in some patients, and over the long term, these side-effects could reasonably be expected to reduce the motivation, if not the ability, to perform normal tasks. By some definitions, these effects could also be regarded as behaviourally toxic.

One fundamental difference between depressed patients and healthy volunteers is that the former are ill and therefore have the capacity to respond favourably to antidepressants, whereas the latter can only experience side-effects. The rationale for studying these drugs' effects in volunteers is that the impairments they show are due to side-effects, as in patients. This may well be true for patients at the beginning of antidepressant therapy before the onset of a therapeutic response, as well as for the unfortunate minority who experience no remission of symptoms despite receiving a full course of treatment. However, the net influence of any of these drugs on responders' behaviour always reflects the balance between persistently impairing side-effects and the beneficial therapeutic effect. Moreover, the drug effect on behaviour is always superimposed upon whatever disease effects were there in the first place.

Whenever patients' psychomotor or cognitive performance before the initiation of antidepressant therapy has been compared to that of matched, nondepressed patients or normal controls, the former have scored worse than the latter (Seppälä et al, 1978; Weckowicz et al, 1978; Cohen et al, 1982; Peselow et al, 1991; Austin et al, 1992). The initial degree of impairment correlated significantly with rating scale assessments of the severity of depression in Austin et al's study, while all studies so far mentioned, plus those of Hobi et al (1982), Siegfried \& O'Connolly (1986) and Moon \& Davey (1988), showed that patients' performance improved along with their mood, regardless of the antidepressants used. Peselow et al demonstrated that memory improvement in responders to imipramine therapy brought them up to the same levels as normal controls after 4 weeks. On the other hand, nonresponders remained significantly deficient, relative to both of the other groups. However, the rate of performance improvement during antidepressant therapy is determined in part by sedative side-effects: groups treated with less sedative drugs improved more rapidly in both Seppälä et al's and Siegfried \& O'Connolly's studies. It cannot be said that the 
proposed system reflects either the subnormal baseline performance of patients or their subsequent net improvement during effective drug therapy. It could be argued that this system at least provides the means of predicting relative rates of patients' behavioural improvement during therapy with different antidepressants. But predicting relative rates of improvement is a different matter from discriminating between 'behavioural toxicities'.

Studies supporting the 'behavioural toxicity', system are apparently based on two assumptions: that antidepressants' acute effects on performance good, bad or neutral - persist unabated for as long as the drug is taken, and that no new side-effects of behavioural consequence emerge with chronic dosing. The first assumption is clearly at odds with data collected in many studies on healthy volunteers where dosing continued over 1-3 weeks. For several reasons, including (but not limited to) its sedating activity, amitriptyline is the most impairing antidepressant. Yet even this drug's acute adverse effects on the psychomotor performance of the volunteers generally diminished to the point of non-significance after the drug was taken in divided and/or nocturnal doses of $75 \mathrm{mg}$ daily for one or two weeks (Seppälä et al, 1984; Lader et al, 1986; Allen et al, 1988; Robbe et $a l$, in press). The acute effects of many other sedating antidepressants on psychomotor performance have likewise been shown to dissipate rapidly as tolerance develops, even when their doses were within the adult therapeutic range (e.g. clomipramine $50 \mathrm{mg}$ t.d.s. Allen et al, 1991; dothiepin 150 mg nocte - Ramaekers et al, in press). Indeed, one is hard pressed to find any study undertaken with either volunteers or depressed patients treated with any antidepressant where signs of tolerance for sedation affecting performance failed to occur. Tolerance may or may not entirely overcome the impairing effect seen after a single dose of a sedating antidepressant, depending on the drug and dose, but since that is a potent ameliorating factor, it limits the generalisations that should be made from single-dose studies.

SSRIs which have no acute effects on performance have sometimes been shown to produce mild impairment after prolonged administration to healthy voluneers. For instance, vigilance test performance and the critical fusion frequency threshold both declined significantly over 3 weeks in volunteers treated with fluoxetine $20 \mathrm{mg}$ nocte (Ramaekers et al, in press). Similarly, fluvoxamine $25 \mathrm{mg}$ t.d.s. for one week followed by $50 \mathrm{mg}$ t.d.s. for the second week potentiated the adverse effects of a dose of alcohol sufficient to achieving a blood concentration of $50 \mathrm{mg} / \mathrm{dl}$ : impairment of psychomotor performance after the combination was significantly greater than that following either agent alone. Moreover, the degree of impairment was greater after the second than after the first week of treatment (Herberg \& Menke, 1981).

If reliable discrimination is to be achieved between the behaviourally toxic effects of different antidepressants, this should be based upon data from subjects treated for at least long enough for the drugs' plasma concentration to arrive at pharmacological steady state, or preferably, until a therapeutic response would occur in depressed patients. This view was recently endorsed by $88 \%$ of an international group of 41 experts participating in a questionnaire survey for the purpose of establishing methodological guidelines for assessing medicinal drug effects on driving performance (Vermeeren et al, 1994).

Indeed, there is good reason to develop a better categorisation system of this kind, not only for antidepressants but for all psychoactive drugs. Two epidemiological surveys in the US show that some drugs probably do have a behaviourally toxic effect, as can be quantified by the users' increased risk of traffic accident involvement. Nelson (1986, unpublished) undertook a retrospective case-control survey using the driving histories and medical records from women patients treated for all reasons at the Mayo Clinic in Rochester, Minnesota during 1977-81. Diagnosed depressed patients were 1.78 times $(P<0.05)$ more likely to become involved in traffic accidents than those suffering from any other disorder. However, patients treated with the then available drugs (all tricyclics) were less likely, and those not treated with drugs, more likely, to become accident victims (1.25 times (NS) and 4.4 times, $P<0.05$ ). Nelson was not concerned with the relative risks of accident involvement of groups using particular antidepressants. But when we applied his formula to the data it emerged that, among depressed patients, those taking amitriptyline drove with an accident risk 4.9 times $(P<0.05)$ higher than those taking another tricyclic or nothing.

Ray et al (1992) carried out a retrospective cohort study from the Medicaid prescription records and traffic records of elderly (over 65) Tennessee residents during 1984-88. Current users of all types of psychoactive drugs were 1.5 times $(P<0.05)$ more frequently involved in injurious accidents, and the users of tricyclic antidepressants, predominantly amitriptyline (50\%) were $\mathbf{2 . 2}$ times more frequently involved, than non-users. Moreover, the relative risk was related to the prescribed dose. The users of recommended doses for this age group (i.e. up to $75 \mathrm{mg} /$ day) drove with up to double the normal risk but those treated with more than $125 \mathrm{mg} /$ day had 5.5 times as many accidents as the non-users.

Taken together these results indicate that depression is itself a cause of traffic accidents and that most 
of the antidepressant drugs used in America until the late 1980 s reduced the patients' risk. The only exception appears to have been amitriptyline; that drug alone, especially when given in high doses, can rightfully be labelled as behaviourally toxic on the basis of epidemiological evidence.

Does this confirm the proposed categorisation system? In a limited sense it does. One antidepressant which it labels as behaviourally toxic apparently is so. But no support exists for applying the same label to other drugs and none exists for declaring any drug free from behavioural toxicity on the basis of single-dose experiments.

Depression itself and the chronic use of one antidepressant, amitriptyline, are associated with a greater than normal risk of traffic accidents. Otherwise, impairments associated with depression generally resolve in those patients showing a favourable response to antidepressant therapy, regardless of the drug. The responses of healthy volunteers to single doses of different drugs have not been shown to predict their net effects on patients' performance abilities during longterm therapy, but may either under- or overestimate any adverse drug effects which emerge or dissipate with repeated doses. Because of the real possibility that chronic drug effects may differ from those measured after single doses, and because chronic effects are much more relevant for patients' safety than the effects of single doses, there is a continuing need for developing a valid system to categorise the behavioural toxicities of antidepressants.

\section{References}

Alford, C. \& Hindmarch, I. (1990) Measuring the effects of psychoactive drugs, with particular reference to antidepressants. In Microcomputers, Psychology and Medicine (eds R. West, M. Christie \& J. Weinman). New York: Wiley.

Allen, D., LADER, M. \& CuRran, v. (1988) A comparative study of the interactions of alcohol with amitriptyline, fluoxetine and placebo in normal subjects. Progress in Neuropsychopharmacology and Biological Psychiatry, 12, 63-80.

-, Curran, H. V. \& Lader, M. (1991) The effects of repeated doses of clomipramine and alprazolam on physiological, performance and cognitive functions in normal subjects. European Journal of Clinical Pharmacology, 40, 355-362.

Austin, M.-P., Ross, M., Murray, C., et al (1992) Cognitive function in major depression. Journal of Affective Disorders, 25, 21-30.

Cohen, R. M., Weingartner, H., Smallberg, S. A., el al (1982) Effort and cognition in depression. Archives of General Psychiatry, 39, 593-597.

Herberg, K. W. \& MenKe, H. (1981) Study of the effects of the Antidepressant Fluvaxamine on Driving Skills and its Interaction With Alcohol. Technical Report, Köln: TÜV Rheinland.

HiNDMARCH, I. \& KerR, J. (1992) Behavioral toxicity of antidepressants with particular reference to moclobemide. Psychopharmacology, 106, S49-S55.

Hobi, V., GASTPAR, M., GASTPAR, G., et al (1982) Driving ability of depressive patients under antidepressants. Journal of International Medical Research, 10, 65-81.

KerR, J. S., Sherwood, N. \& Hindmarch, I. (1992) The comparative psychopharmacology of SHT reuptake inhibitors. Human Psychopharmacology, 6, 313-317.

Lader, M., Melhuish, A., Freka, G., et al (1986) The effects of citralopram in single and repeated doses and with alcohol on physiological and psychological measures in healthy subjects. European Journal of Clinical Psychopharmacology, 31, 183-190.

Moon, C. A. L. \& Davey, A. (1988) The efficacy and residual effects of trazodone (150 $\mathrm{mg}$ nocte) and mianserin in the treatment of depressed general practice patients. Psychopharmacology, 95, S7-S13.

Nelson, R. C. (1986) Psychotherapeutic Drugs, Mental Disorders and Automobile Crashes: a Case-Control Study of 1308 Females. Unpublished Doctoral Dissertation, University of Minnesota.

Peselow, E. D., Corwin, J., Fieve, R. R., et al (1991) Disappearance of memory deficits in outpatient depressives responding to imipramine. Journal of Affective Disorders, 21, 173-183.

Ramaekers, J. G., MuntJewerff, N. D. \& O'Hanlon, J. F. (1995) A comparative study of acute and subchronic effects of dothiepin, fluoxetine and placebo on psychomotor and actual driving performance. British Journal of Clinical Pharmacology, in press.

RAY, W. A., Fought, R. L. \& Decker, M. D. (1992) Psychoactive drugs and the risk of injurious motor vehicle crashes in elderly drivers. American Journal of Epidemiology, 136, 873-883.

RoBbE, H. W. J. \& O'Hanlon, J. F. (1995) Acute and subchronic effects of paroxetine and amitriptyline on actual driving, psychomotor performance and subjective assessments in healthy volunteers. European Neuropsychopharmacology, in press.

SEPPÄLÄ, T. (1977) Psychomotor skills during acute and two-week treatment with mianserin (ORG GB 94) and amitriptyline, and their combined effects with alcohol. Annals of Clinical Research, 9, 66-72.

- LinNolla, M., Elonen, E., et al (1975) Effects of tricyclic antidepressants and alcohol on psychomotor skills related to driving. Clinical Pharmacology and Therapeutics, 17, 515-522. - - \& MATtILA, M. J. (1978) Psychomotor skills in depressed outpatients treated with L-tryptophan, doxepin or chlorimipramine. Annals of Clinical Research, 10, 214-221. , Strómberg, C. \& Bergman, J. (1984) Effects of zimelidine, mianserin and amitriptyline on psychomotor skills and their interaction with ethanol: a placebo-controlled crossover study. European Journal of Clinical Pharmacology, 27, 181-189.

SHERWOOd, N. \& HindMARCH, I. (1993) A comparison of five commonly prescribed antidepressants with particular reference to their behavioural toxicity. Human Psychopharmacology, 8, 417-422.

SIEGFrIED, K. \& O'CONNOLLY, M. (1986) Cognitive and psychomotor effects of different antidepressants in the treatment of old age depression. International Psychopharmacology, 1, 231-243.

Vermeeren, A., De Gier, J. J. \& O'Hanzon, J. F. (1994) Methodological Guidelines for Experimental Research on Medicinal Drugs Affecting Driving Performance: an International Expert Survey. Maastricht: University of Limburg Institute for Human Psychopharmacology. Techn. Rep. 93-27, ISBN 90-5147-021-5.

Weckowicz, T. E., TAM, C.-N.I., MAson, I., et al (1978) Speed in test performance of depressed patients. Journal of Abnormal Psychology, 87, 578-582.

James F. O'Hanlon, PhD, Institute for Human Psychopharmacology, University of Limburg, Abstraat 2A, 6211 LS Maastrict, The Netherlands; Hugh Freeman DM, FRCPsych, 21 Montagu Square, London W1H 1RE

Correspondence: Professor Hugh Freeman, 21 Montagu Square, London W1H 1RE

(First received 3 May 1994, final revision 14 September 1994, accepted 7 October 1994) 